\title{
Developmental Expression and Biochemical Analysis of Conulin, a Protein Secreted from a Subset of Neuronal Growth Cones
}

\author{
Diego Sánchez, ${ }^{a}$ María D. Ganfornina, ${ }^{a}$ and Michael J. Bastiani \\ Biology Department, University of Utah, Salt Lake City, Utah 84112
}

In this report, we analyze the developmental pattern of expression of a new grasshopper protein, Conulin, using the monoclonal antibody 7D2 on whole-mount embryos and dissociated neurons. We also have examined its biochemical properties by immunoblot analysis. Conulin is a protein expressed by a subset of neurons in the grasshopper embryo. The monoclonal antibody $7 \mathrm{D} 2$ recognizes Conulin as an $M_{\mathrm{r}} 190 \times 10^{3}$ protein that is found in both the soluble and membrane-bound fractions of embryonic proteins. The membrane association is disrupted by alkaline $\mathrm{pH}$ and high ionic strength. Conulin first is expressed and stored in vesicles inside the cell bodies and axons of central and peripheral neurons. Later, Conulin is detected on the cell surface, but exclusively in the central nervous system neuropil. This expression is confined to a subset of nerve growth cones. Conulin is detected on growth cones only after pioneer neurons have outlined the axonal scaffold. Immunocytochemistry on cultured embryonic neurons demonstrates that the neurons have the autonomous ability to target Conulin to the growth cones. The protein is secreted but remains transiently associated with the growth cone plasma membrane. The discovery of Conulin confirms the existence of proteins specific for the nerve growth cone. Its transitory presence during axonogenesis in only a subset of follower growth cones suggests that Conulin is involved in guidance through selective fasciculation with pre-existing axons within the ganglionic neuropil.

Key words: growth cone-specific protein; secreted protein; grasshopper; selective fasciculation; CNS-specific protein; pathfinding
The specificity required for the proper connectivity in the nervous system is thought to rely on the nerve growth cone, a specialized structure at the tip of every growing neurite. In addition to being the main site for assembling plasma membrane and cytoskeleton, resulting in neurite elongation, this neurite expansion is a sensory structure involved in axon guidance. This role presumably reflects the highly complex array of molecules present at the growth cone surface and organizing a sophisticated signal transduction machinery. Furthermore, growth cones appear to interact actively with their surroundings by releasing substances such as proteolytic enzymes and neurotransmitters (Poo and Quillan, 1992; Seeds et al., 1992). The growth cone can be considered to be a quite autonomous structure, as revealed by the locomotory, sensory detection and transduction, calcium homeostasis, and protein synthesis capabilities demonstrated by isolated growth cones (for review, see Davis et al., 1992) and even by its filopodial protrusions (Davenport et al., 1993). Despite this autonomy, growth cones require signals provided by the environment in the form of short- or long-range cues that can be attractive or repulsive to growth along a definite pathway (Goodman and Shatz, 1993; Tessier-Lavigne, 1994). Growth cones are confronted with different sets of cues in a spatiotemporally heterogeneous manner, and

\footnotetext{
Received July 28, 1995; revised Sept. 26, 1995; accepted Oct. 4, 1995.

${ }^{a}$ M.D.G. and D.S. contributed equally to this work.

This work was supported by National Institutes of Health Grant NS25387 (M.J.B.). M.D.G. held a fellowship from the Fulbright/MEC of Spain, and D.S. was the recipient of National Institutes of Health Postdoctoral Fellowship 1FO57W4686. We thank K. Knobel, E. Laywell, E. Seaver, and A. Westbrook for support and critical reading of this manuscript, and we thank $E$. Carpenter for generating $m A b$ 7D2.

Technical assistance was provided by Macarena Herrera.

Correspondence should be addressed to Diego Sánchez, Biology Department, University of Utah, Salt Lake City, UT 84112.

Copyright $(1996$ Society for Neuroscience $\quad 0270-6474 / 96 / 160663-12 \$ 05.00 / 0$
}

they appear to integrate this assorted molecular information via appropriate receptors for those environmental signals.

Spatially separated regions of a developing neuron can be differentially exposed to environmental cues. Although certain surface molecules related to the processes of neurite outgrowth and axonal guidance appear to be homogeneously expressed on the plasma membrane [for example, see Patel et al., 1987; Karlstrom et al., 1993; Sánchez, Ganfornina, and Bastiani, 1995 (cited hereafter as Sánchez et al., 1995)], others show a spatial restriction to certain axonal regions (Bastiani et al., 1987; Dodd et al., 1988; Kolodkin et al., 1992). In this context, the confinement of molecules to the surface of subsets of growth cones would provide an additional level of specificity to the integrative processes leading to cell recognition and pathfinding. The protein we present in this work is expressed by a subset of nerve growth cones at particular locations within the developing CNS of the grasshopper embryo. Immunocytochemistry with the monoclonal antibody (mAb) 7D2 on whole-mount embryos and primary cultures of dissociated embryonic neurons reveals that this protein is secreted from growth cones and is present transiently in the surrounding extracellular-matrix. Biochemical studies confirm its secreted nature and also suggest an interaction with the plasma membrane surface. We have named this protein Conulin, from the Latin conulus, meaning little cone, because of its selective subcellular localization.

\section{MATERIALS AND METHODS}

Grasshopper (Schistocerca americana) embryos were staged by percentage of embryonic development (hatching in $20 \mathrm{~d}$ ) according to Bentley et al. (1979). The mAb 7D2 was generated by Carpenter and Bastiani (1990) against embryonic nerve tissue using a subtractive immunization method. Ascites fluid was generated in Balb/c and athymic (B6CByF1) mice (Jackson, West Grove, PA).

Immunocytochemistry. The antibody labeling protocol for whole-mount grasshopper embryos is detailed in Sánchez et al. (1995). Differential 
interference contrast (DIC) microscopy was used to analyze the preparations. To examine Conulin expression pattern in grasshopper embryos ranging from 60 to $100 \%$ of development, nerve cords were dissected and the standard protucol was carried out with longer antibody incubation times (3-6 d for the primary and 18-24 hr for the secondary antibody).

Embryonic neuronal primary cell culture. A modified version of the procedures by Laurent et al. (1993) was followed. Embryos at $45 \%$ of development were dissected in culture medium containing $50 \%$ Schneider's Drosophila medium (Gibco, Gaithersburg, MD), 49\% minimum essential medium ( $\alpha$ medium, Gibco), and $1 \%$ antibiotic-antimycotic solution (Sigma, St. Louis, MO). Embryonic nerve cords were dissected and enzymatically treated for $5 \mathrm{~min}$ at $32^{\circ} \mathrm{C}$ in medium containing 0.17 $\mathrm{mg} / \mathrm{ml}$ collagenase (Worthington Biochemical, Freehold, NJ), $0.5 \mathrm{mg} / \mathrm{ml}$ dispase (grade II, Boehringer Mannheim, Indianapolis, IN), and 0.1 $\mathrm{mg} / \mathrm{ml}$ DNase (type I, Bochringer Mannheim). The digested nerve cords were dispersed mechanically with a siliconized and fire-polished Pasteur pipette, spun at $325 \times g$ for $6 \mathrm{~min}$, washed with medium, and spun again a total of three times. After the final wash, dispersed cells were resuspended in $200 \mu \mathrm{l}$ of medium and plated on glass coverslips coated with 1 $\mathrm{mg} / \mathrm{ml}$ poly-L-lysine, $200 \mu \mathrm{g} / \mathrm{ml}$ concanavalin A, and $2 \mu \mathrm{g} / \mathrm{ml}$ laminin (all obtained from Sigma). The cells were allowed to attach to the substrate for $15 \mathrm{~min}$ in a $35 \mathrm{~mm}$ Petri dish, and then $4 \mathrm{ml}$ of medium was added. Cells were incubated for $48 \mathrm{hr}$ at $32^{\circ} \mathrm{C}$ with $5 \% \mathrm{CO}_{2}$. After incubation, the cells were fixed in $4 \%$ formaldehyde in medium for $15 \mathrm{~min}$ at room temperature, washed with medium three times for $10 \mathrm{~min}$, blocked with $30 \mathrm{mg} / \mathrm{ml}$ bovine serum albumin (Sigma) and $2 \%$ normal goat serum (Gibco), exposed to $\mathrm{mAb} 7 \mathrm{D} 2(1: 1000)$ at room temperature for $30 \mathrm{~min}$, washed again, and blocked and incubated for $30 \mathrm{~min}$ in Cy3-conjugated goat anti-mouse IgG (1:500, Jackson). Findlly, the cells were washed and mounted in PBS and viewed with DIC and epifluorescence on a Leitz microscope.

Immunoprecipitation and immunoblot analysis of embryonic proteins. Membrane protein preparation and immunoprecipitation procedures were performed as described by Seaver et al. (1991). Preformed antibody complexes with mAbs 3B11, 13E10, and 7D2 and rabbit serum antimouse IgG (Jackson) were used. Immunoprecipitated ${ }^{125}$ I-labeled proteins were separated by SDS-PAGE under reducing conditions, and the gel was dried and exposed to film. Immunoblot analysis of both soluble and immunoprecipitation buffer (IPB)-solubilized proteins [10 $\mathrm{mM}$ tetraethanolamine (TLA), pII 7.8, $150 \mathrm{~mm} \mathrm{NaCl,} 1 \%$ Nonidet P-40 (NP-40)] was performed with mAb 7D2 as described previously [Ganfornina, Sánchez, and Bastiani, 1995 (hereafter cited as Ganfornina et al., 1995)].

Biochemical characterization of Conulin. To analyze the association of Conulin with the plasma membrane, high salt and/or basic $\mathrm{pH}$ extractions were carried out. Membrane proteins from grasshopper embryos were separated from the soluble fraction, and unsolubilized membranes were subjected to a basic pH buffer (10 mM TEA, pH 11.3, $150 \mathrm{~mm} \mathrm{NaCl),} \mathrm{a}$ high salt buffer (10 mM TEA, pH $7.8,500 \mathrm{mM} \mathrm{NaCl})$, or a combination of both conditions $(10 \mathrm{mM}$ TEA, $\mathrm{pH} 11.3,500 \mathrm{mM} \mathrm{NaCl})$ for $30 \mathrm{~min}$ on ice with occasional vortexing and a short pulse $(5 \mathrm{sec})$ of sonication at low energy. The mixture was diluted 10 fold with the buffer used for the extraction and centrifuged $(100,000 \times g, 2 \mathrm{hr})$. The supernatants were dialyzed against $10 \mathrm{~mm}$ TEA, $\mathrm{pH} 7.8,150 \mathrm{mM} \mathrm{NaCl}$ buffer and concentrated with Centricon-10 (Amicon, Beverly, MA), and membrameassociated proteins were solubilized with IPB. Both fractions were separated by SDS-PAGE and analyzed by immunoblot using $\mathrm{mAb}$ 7D2. Analysis of glycosyl-phosphatidylinositol (GPI) anchoring to the membrane was carried out as described by Ganfornina et al. (1995).

To determine whether Conulin is a glycoprotein, membrane-bound and soluble embryonic proteins were subjected to chemical or enzymatic deglycosylation. The soluble fraction of a membrane preparation was lyophilized, dissolved in $200 \mu$ of a precooled mixture of trifluoromethanesulphonic acid (TFMS; Sigma) with Anisole (2:1) (Aldrich, Milwaukee, WI), and incubated for $1 \mathrm{hr}$ on ice and $2 \mathrm{hr}$ at $-20^{\circ} \mathrm{C}$, and the reaction was stopped by adding $10 \mu \mathrm{l}$ of $2 \mathrm{M}$ Tris buffer, pII 8.0. For enzymatic deglycosylation, detergent-soluble proteins were denatured with $10 \mathrm{~mm} \beta$-mercaptoethanol and by boiling for $5 \mathrm{~min}$ and then were incubated with $3.3 \mathrm{U} / \mathrm{ml}$ peptide- $N$-glycosidase F (PNGase F, Boehringer Mannheim) at $37^{\circ} \mathrm{C}$ for $18 \mathrm{hr}$. Membrane proteins were also heatdenatured and incubated with $0.15 \mathrm{mU} / \mathrm{ml}$ neuraminidase (from $A r$ throbacter ureafaciens, Sigma) at $37^{\circ} \mathrm{C}$ for $18 \mathrm{hr}$. The reaction was stopped by adding electrophoresis sample buffer. Control protein was also denatured and incubated without enzyme. Deglycosylated proteins were separated by SDS-PAGE, transferred to a nitrocellulose membrane, and analyzed by immunoblot.
Affinity purification of Conulin. Embryonic lysate preparation was modified from Bastiani et al. (1987). Eggs were dechorionated, washed, and homogenized in PBS buffer (10 mm sodium phosphate, $\mathrm{pH} 7.4,150 \mathrm{~mm} \mathrm{NaCl}$ ) with protease inhibitors $(\mathrm{PI})$ at $4^{\circ} \mathrm{C}$ using a blender. Particulate and insoluble material was pelleted at $23,000 \times g$ for $30 \mathrm{~min}$. The supernatant, representing soluble material, was filtered through a sterile nylon membrane and stored at $-70^{\circ} \mathrm{C}$ with $0.04 \%$ sodium azide. The pellet was incubated in lysate buffer (10 mM TEA, pH 8.2, $150 \mathrm{~mm} \mathrm{NaCl,} 2 \%$ NP-40, $0.5 \%$ deoxycholate) with PI stirring at $4^{\circ} \mathrm{C}$ for $2-4 \mathrm{hr}$. Insoluble material was removed by centrifugation $(23,000 \times \mathrm{g}, 30 \mathrm{~min})$, and the supernatant, representing detergent-solubilized proteins, was filtered and stored at $-70^{\circ} \mathrm{C}$ with $0.04 \%$ sodium azide. Total protein concentration was measured with the MicroBCA assay (Pierce, Rockford, IL). Conulin was purified by affinity chromatography using mAb 7D2 from detergent-soluble fractions of embryonic lysates as described previously (Bastiani et al., 1987). Conulin also was purified from the soluble fraction of embryonic lysates. In this case, the protein was eluted with $50 \mathrm{~mm}$ triethylamine, $\mathrm{pH} 11.5$, and $150 \mathrm{mM} \mathrm{NaCl}$, dialyzed against $0.1 \mathrm{M}$ Tris buffcr, $\mathrm{pH} 8.0$, and concentrated with Centricon-50 (Amicon).

\section{RESULTS \\ Conulin is a developmentally regulated protein specific to the CNS}

The main axonal pathways of the metameric ganglia of the grasshopper CNS are established at $\sim 35 \%$ of embryonic development. Pioneer neurons organize a scaffold consisting of two commissures (anterior and posterior) that connect hemiganglia, two connectives running longitudinally and connecting ganglia, and a median fiber tract located dorsally at the midline. Many new axons subsequently fasciculate with and follow these pre-existing pathways. The CNS connection with the periphery is channeled through the segmental (SN) and intersegmental (ISN) nerves.

The $\mathrm{mAb}$ 7D2 recognizes a cell-surface molecule as revealed by in wivo labeling of whole-mount embryos. The antigen is expressed during a precise temporal window; it is detected first at $33 \%$ of embryonic development, continues to be expressed until $\sim 80 \%$ of development, and is absent during postembryonic development and adulthood. A striking feature of this antigen is its absolute specificity to the nervous system, particularly to the CNS. As seen in the embryos shown in Figure 1, $A$ and $B$ (55 and $70 \%$ of development, respectively), the labeling pattern is restricted to the ventral nerve cord of the embryo. The first labeling is observed associated with a single bundle of axons contributing to the primary commissure of the brain (Fig. $1 C$ ). In the segmental ganglia, the 7D2 antigen initially appears at $35 \%$ of development after the first pioneer neurons already have laid down an axonal scaffold. Labeling is associated with an identified axon bundle at the anterior border of the $\mathrm{SN}$ (out of focus in Fig. 1D), which is pioneered by the AsM neurons (Sánchez et al., 1995). Subsequently, Conulin appears to be associated with a fascicle of the posterior bundle of the anterior commissure (Fig. 1D) pioneered by Fasciclin I-expressing neurons (Bastiani et al., 1987). Later, the expression pattern becomes more complex, and other labeled axon bundles appear (Fig. 1E), such as one in the posterior commissure pioneered by the Q1 cells. Nevertheless, labeling is present only on a subset of fascicles and is remarkably absent from the longitudinal connectives, the ISN, and the peripheral SN (see Figs. $1 B, 2 D, 8 B$ ). This restricted pattern is unique compared with other neuronal subset-specific molecules. In older embryos, the labeling remains restricted to the neuropilar region of the segmental ganglia (Fig. 1B) and brain (data not shown). In summary, the labeling pattern obtained with $\mathrm{mAb} 7 \mathrm{D} 2$ indicates that Conulin is dynamically and regionally expressed in association with a subset of axon bundles in the CNS during grasshopper embryogenesis.

Before the first labeling appears on the cell surface, there are large, round-labeled granules in neuronal cell bodies and along 

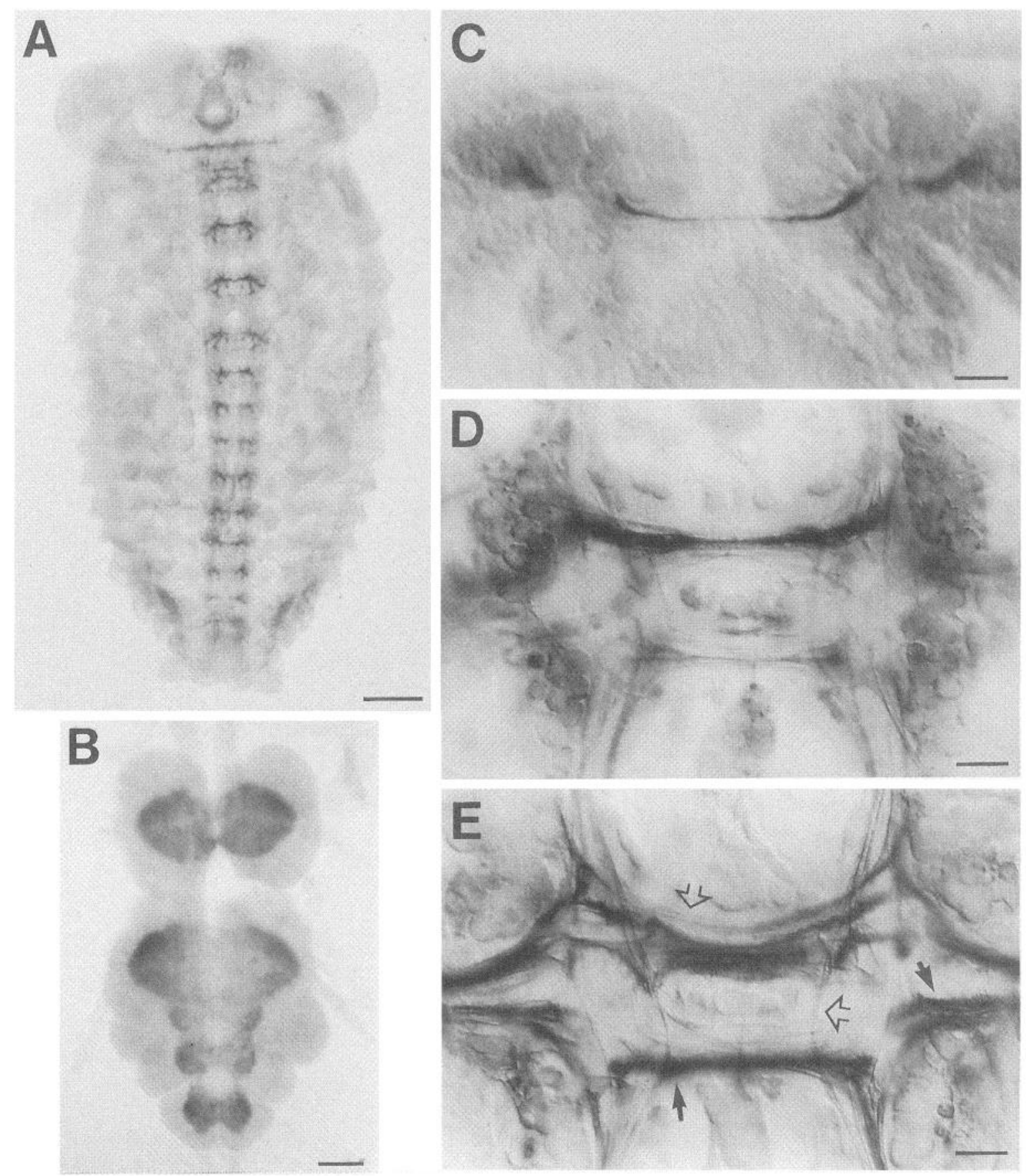

Figure 1. The expression of Conulin is developmentally regulated and specific to the CNS as seen by immunolabeling of whole-mount grasshopper embryos with mAb 7D2. Embryos are viewed from the dorsal surface with DIC optics. Anterior is up. A, Grasshopper embryo at $55 \%$ of development. No labeling is seen outside the CNS, which lies at the ventral midline of the embryo. B, Labeling pattern at the neuropilar region of the T2-A3 ganglia in a $70 \%$ embryonic grasshopper nerve cord. $C$, The earliest expression appears (33\% of development) on a single axon fascicle in the primary commissure of the brain. $D, E$, mAb 7D2 labeling pattern in a thoracic ganglion of embryos at 36 and $45 \%$ of development, respectively, showing the subset of axon tracts labeled by $7 \mathrm{D} 2$. Arrows indicate labeled fascicles; open arrows indicate unlabeled fascicles. Scale bars: $A, 250 \mu \mathrm{m} ; B, 100 \mu \mathrm{m} ; C, 50 \mu \mathrm{m} ; D, E, 25 \mu \mathrm{m}$.

axons. These granules are present in a fairly large number of cell bodies (Fig. $2 A$ ) including the pioneer neurons MP1, MP4, and Q1. This contrasts with the low number of fascicles where Conulin is detected and also with the absence of surface labeling on pioneer axons. The punctate labeling can also be seen in the cell bodies and axons of neuronal sensory clusters, such as the dorsal body wall group of the ISN (Fig. 2B, $d B w$ ), whereas no surface labeling is observed along the nerve trajectory outside the CNS. However, not every neuron displays this punctate pattern, and several groups of cells in both metameric ganglia (data not shown) and brain (Fig. 2C) do not show this pattern. Interestingly, the granular labeling only occurs in fixed and permeabilized embryos. This suggests that Conulin is being stored in an intracellular membranous compartment and is transported by an array of vesicles along the axons.

The surface presence of Conulin also seems to be transitory, as inferred from the differences in labeling commonly found in 

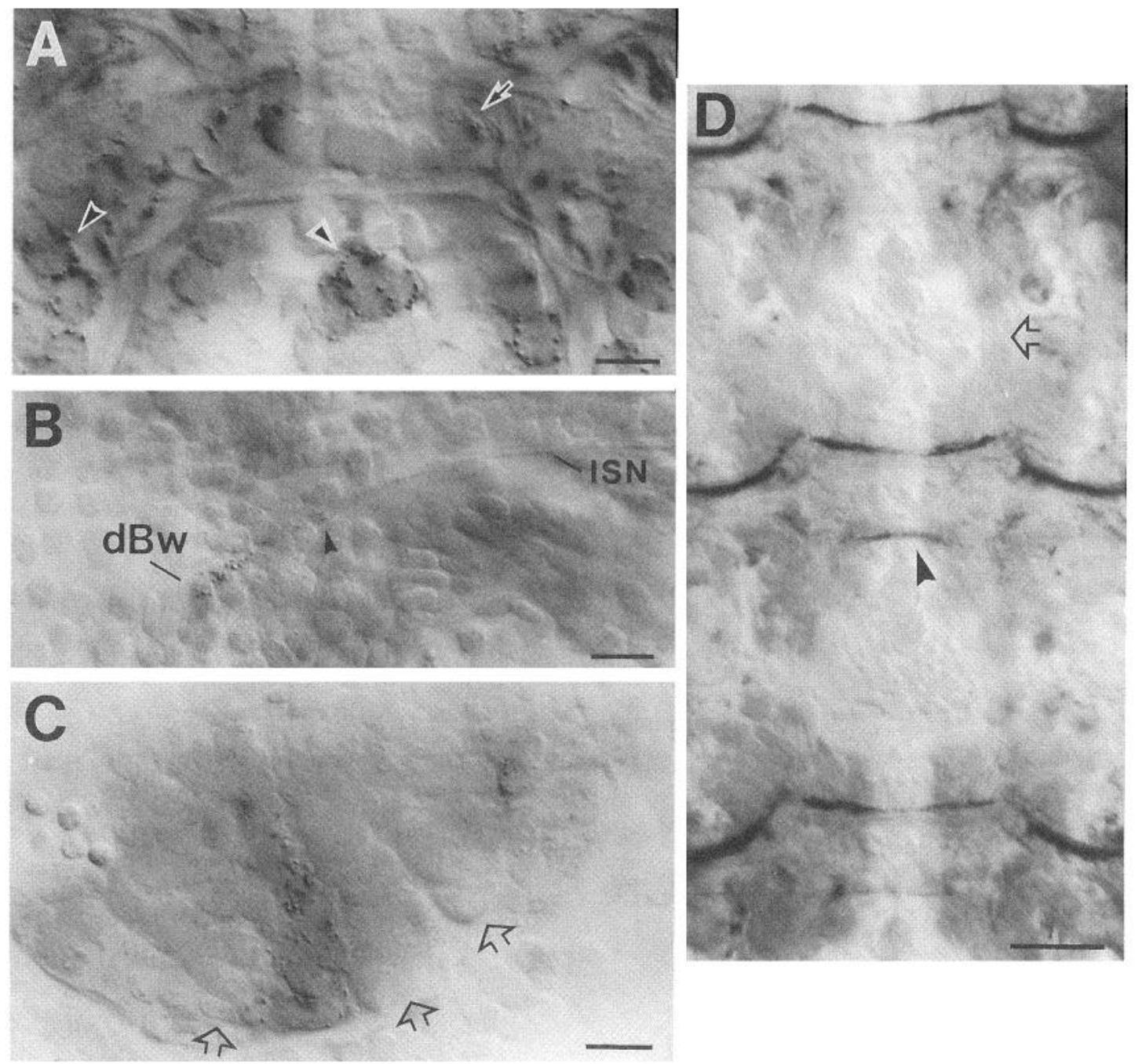

Figure 2. Intracellular granules labeled with $\mathrm{mAb} 7 \mathrm{D} 2$ appear in a subset of cells in the CNS and PNS after pioneer axons have already defined the axonal scaffold. $A$, Vesicular pattern of a segmental ganglion at 34\% of development. Several pioneer neurons such as Q1 (arrowhead), MP1 (arrow), and MP4 (triangle) are identified. $B$, A particular group of cells in the peripheral nervous system (dorsal body wall group, $d B w$ ) also displays vesicles, but no labeling is detected on their axons before they enter the CNS, which is out of view to the right. Arrowhead identifies vesicles along the sensory axon traveling toward the CNS through the ISN. C, Column-like groups of cells representing single-neuroblast lineages in the brain lacking the punctate intracellular labeling (open arrows). Midline is to the right. $D$, Conulin expression is transitory. In this example, a fascicle of the posterior commissure of a T2 ganglion (arrowhead) is labeled, whereas the same fascicle in the younger T1 or the older T3 segment does not appear labeled. Note the absence of labeling in the longitudinal connectives (open arrow). Scale bars: $A, C, 20 \mu \mathrm{m} ; B, 25 \mu \mathrm{m} ; D, 75 \mu \mathrm{m}$.

chronologically successive metameric segments. In Figure $2 D$, the labeling associated with a fascicle in the posterior commissure of a T2 ganglion is apparent (arrowhead), whereas it is absent in both the $\mathrm{T} 1$ and $\mathrm{T} 3$ ganglia. It is important to note that the expression seems to be intermittent, because the same commissural fascicle is labeled again later in development.

\section{Restricted localization of Conulin to a subset of nerve growth cones}

The specificity for the nervous system, the restriction to a subpopulation of nerve cells, and its developmental regulation make the 7D2 antigen an interesting candidate for a guiding role in the developing nervous system. However, the most important property of the expression pattern is the cytological confinement of Conulin to the surface of nerve growth cones. Figure $3 A-C$ shows examples of embryonic grasshopper neurons displaying Conulin at the leading edge of growing neurites as revealed by mAb 7D2 immunocytochemistry. The absence of labeling on the rest of the neurite is indicated by open arrows. It is important to note that Conulin expression is not a general property of every growth cone but is restricted to a definite subset of them. Labeled (arrowhead) and unlabeled (open arrows) growth cones are found in the same pathway (Fig. $3 D$ ) or in close apposition but in different fascicles (Fig. 3E). Identified cells displaying 7D2-labeled vesicles (e.g., AsM or Q5 neurons) send their axons through pathways where Conulin-positive growth cones navigate. In particular cases, we were able to follow the axon from the growth cone to the cell body (see Fig. $3 A$ ), and our observations indicate that the same neurons that synthesize Conulin and store it in vesicles are the ones displaying it at the growth cones at particular positions during their navigation.

We determined the location of 7D2-positive growth cones and found a correlation between the expression of Conulin and particular growth cone behaviors. Most of the singly-observable labeled growth cones appear to be in areas in which they select 
different pathways to follow. In Figure 3, $F$ and $G$, we show two different growth cones that are expressing Conulin while they are making pathway choices. One of them is turning and abandoning an axon bundle (Fig. $3 F$ ), whereas the other seems to be steering while recognizing a single unlabeled axon and fasciculating with it (Fig. $3 G$ ). Growth cones are also labeled when following particular fascicles at the commissures (Fig. $3 H$ ) or the SN exits, which suggests that the observed fascicle labeling is the result of several consecutive growth cones walking along an axon bundle. However, growth cones expressing Conulin are seen only on a subset of fascicles. For example, 7D2-positive growth cones are observed only on three of the eight fascicles composing the anterior commissure and two of the six fascicles of the posterior commissure in a T3 ganglion of an embryo at $45 \%$ of development. Growth cones expressing Conulin are seen joining these same fascicles throughout the rest of the expression period, whereas other fascicles are never seen with Conulin-positive growth cones.

The localization of growth cones expressing Conulin over a limited region of a fascicle suggests a downregulation of protein expression once the growth cones reach the boundary of that region. Based on this inference, and on the observation that neurites extend usually by adding new membrane to the growth cone (Bray, 1970, 1973), one should find cells in which Conulin still persists on the neurite, but the advancing growth cone appears unlabeled with mAb 7D2. These cases indeed do exist, and an example is shown in Figure $3 I$. Three 7D2-positive axons, running along the most posterior fascicle of the anterior commissure, present unlabeled growth cones once they leave the commissure to follow different axonal pathways. This "turning off" of Conulin is consistent with the transient and intermittent expression described above (see Fig. 2D).

We assayed whether the restriction of Conulin to growth cones was cell-autonomous or triggered by growth conc interactions with the environment. Primary cultures of embryonic grasshopper neurons were prepared to analyze Conulin expression in dissociated neurons. The culture cell density obtained from two nerve cords at $45 \%$ of development was $1-2 \times 10^{4}$ cells $/ \mathrm{ml}$. Based on immunocytochemistry with the general neuronal marker antihorseradish peroxidase (HRP), we estimated the percentage of neurons in the cultures after $48 \mathrm{hr}$ to be $39.4 \pm 9.7 \%(n=10)$. Immediately after plating, most of the dissociated neurons are devoid of processes. By $48 \mathrm{hr}$ in culture, neurites have extended long distances, and abundant filopodia are observed arising from neuronal cell bodies and neurites as revealed by anti-HRP labeling (Fig. 4A). Immunocytochemistry with mAb 7D2 in nonpermeabilized cultures after fixation revealed the presence of Conulin on the surface of neurons and, more significantly, concentrated at the leading edge of neurites, growing without apparent interaction with other cells (Fig. $4 B, C$ ). Another interesting finding was that, as in the embryo, Conulin is expressed by a subpopulation of neurons, for example, only one of six neurons is labeled in Figure $4, B$ and $C$. Moreover, a punctate labeling resembling large vesicles appears in cell bodies when primary cultures are fixed and permeabilized with $0.2 \%$ Triton X-100 (Fig. $4 D, E$, arrows). All of these labeling features faithfully reflected the labeling pattern and subcellular localization of the protein obtained in whole-mount embryos. Several control antibodies were used to test the extent of permeabilization and the possibility of membrane disruption by the fixation procedure. Experiments with $\mathrm{mAb} 10 \mathrm{E} 6$, which recognizes the surface protein Lazarillo (Ganfornina et al., 1995), the serum anti-HRP, as a general neuronal surface marker, and sera against the cytoplasmic proteins actin and tubulin demonstrated the absolute requirement of detergents to obtain intracellular labeling (data not shown). Experiments exposing cells only to secondary antibodies resulted in the absence of labeling (data not shown).

These results indicate that dissociated cells have the autonomous ability to target Conulin, probably via an array of transport vesicles, to the nerve growth cone. This is consistent with the selective addition of membrane proteins at axonal growth cones observed by Craig et al. (1995).

\section{Biochemical characterization of Conulin}

Immunoprecipitation of iodinated, detergent-soluble proteins of embryos at $45 \%$ of development with mAb 7D2, and subsequent analysis by SDS-PAGE, identifies a specific protein with $M_{\mathrm{r}} 190 \times$ $10^{3}$ (Fig. 5A). A similar band is also detected by immunoblot analysis of detergent-soluble proteins from embryos at 45 and $70 \%$ of development (Fig. $5 B$, lanes 2 and 3 , respectively), which agrees with the developmental expression time course described above. Conulin can be purified from detergent-soluble embryonic lysates by affinity chromatography using mAb 7D2 (Fig. 5B, lane 4). However, the yield from these purification experiments was low $(0.2 \mathrm{ng} / \mathrm{mg}$ total protein $)$, as estimated from silver-stained gels.

$\mathrm{mAb} 7 \mathrm{D} 2$ labeling in vivo suggested that Conulin is on the extracellular side of the plasma membrane. We studied the type of membrane association by releasing GPI-anchored proteins with phosphatidylinositol-specific phospholipase C. This enzymatic treatment did not separate Conulin from the membrane fraction, as evidenced by mAb labeling and immunoblot analysis (data not shown). However, the treatment effectively removed two other known GPI-linked proteins, Lazarillo (Ganfornina et al., 1995) and Fasciclin I (Hortsch and Goodman, 1990). Exposure of 45\% cmbryonic detergent-soluble proteins to a high ionic strength and/or a basic $\mathrm{pH}$ solution can release Conulin which, after separation by SDS-PAGE, is detected in the post-treatment soluble fraction by immunoblot analysis (Fig. $6 A$ ). A quantitative densitometric study of the $M_{\mathrm{r}} 190 \times 10^{3}$ band under different extraction conditions was performed (Fig. 6B). To control for an artifactual release of integral membrane proteins by the treatment, we probed the same fractions with the anti-Lazarillo mAb 10E6. This GPI-linked glycoprotein was never extracted by the treatments (data not shown). Thus, Conulin appears to be associated with the plasma membrane facing the extracellular environment and probably bound by noncovalent and nonhydrophobic interactions to other membrane components. An intriguing finding in these experiments was the presence of Conulin in the soluble fraction of embryo homogenates in an amount higher than the detergent-soluble fraction (Fig. $6 A, B$ ). These results suggest either that the association of Conulin with membranes is so weak that homogenization is enough to release it or that this protein is physiologically secreted to the extracellular environment by the growth cones. When we purify the protein from the soluble fraction of lysates, the yield is $1 \mathrm{ng} / \mathrm{mg}$ total protein of the $M_{\mathrm{r}} 190$ $\times 10^{3}$ band.

To assess the glycosylation state of Conulin, enzymatic (by PNGase F and neuraminidase) and chemical (by TFMS) treatments were carried out on both the soluble and detergent-soluble fractions of embryo homogenates. No detectable change in electrophoretic mobility was observed (Fig. $7 A$, last lane in Fig. $7 B$ ), suggesting that Conulin is not significantly glycosylated. The presence of intra- or interchain disulfide bonds in Conulin was assayed by analyzing its electrophoretic mobility by immunoblot under 

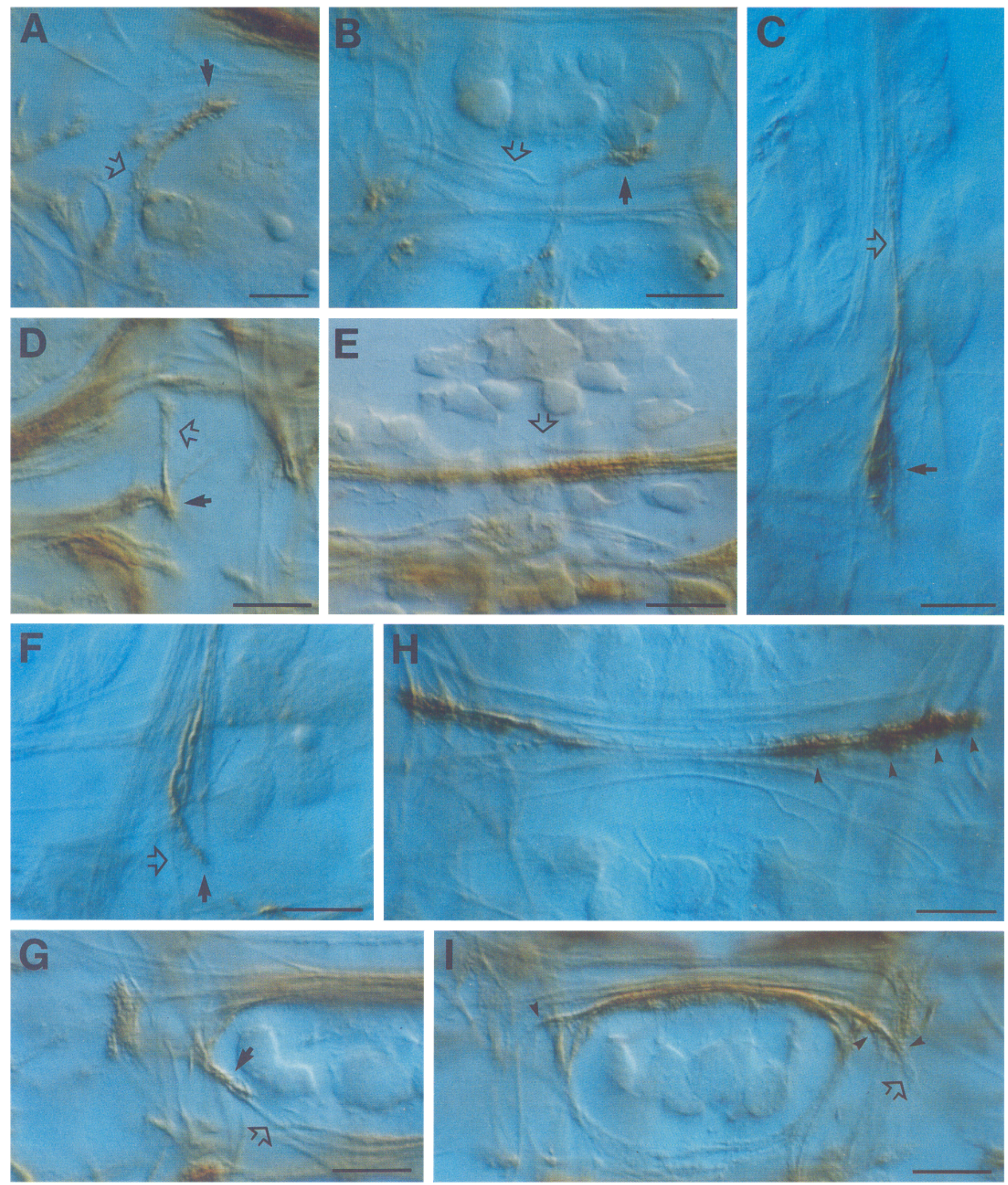


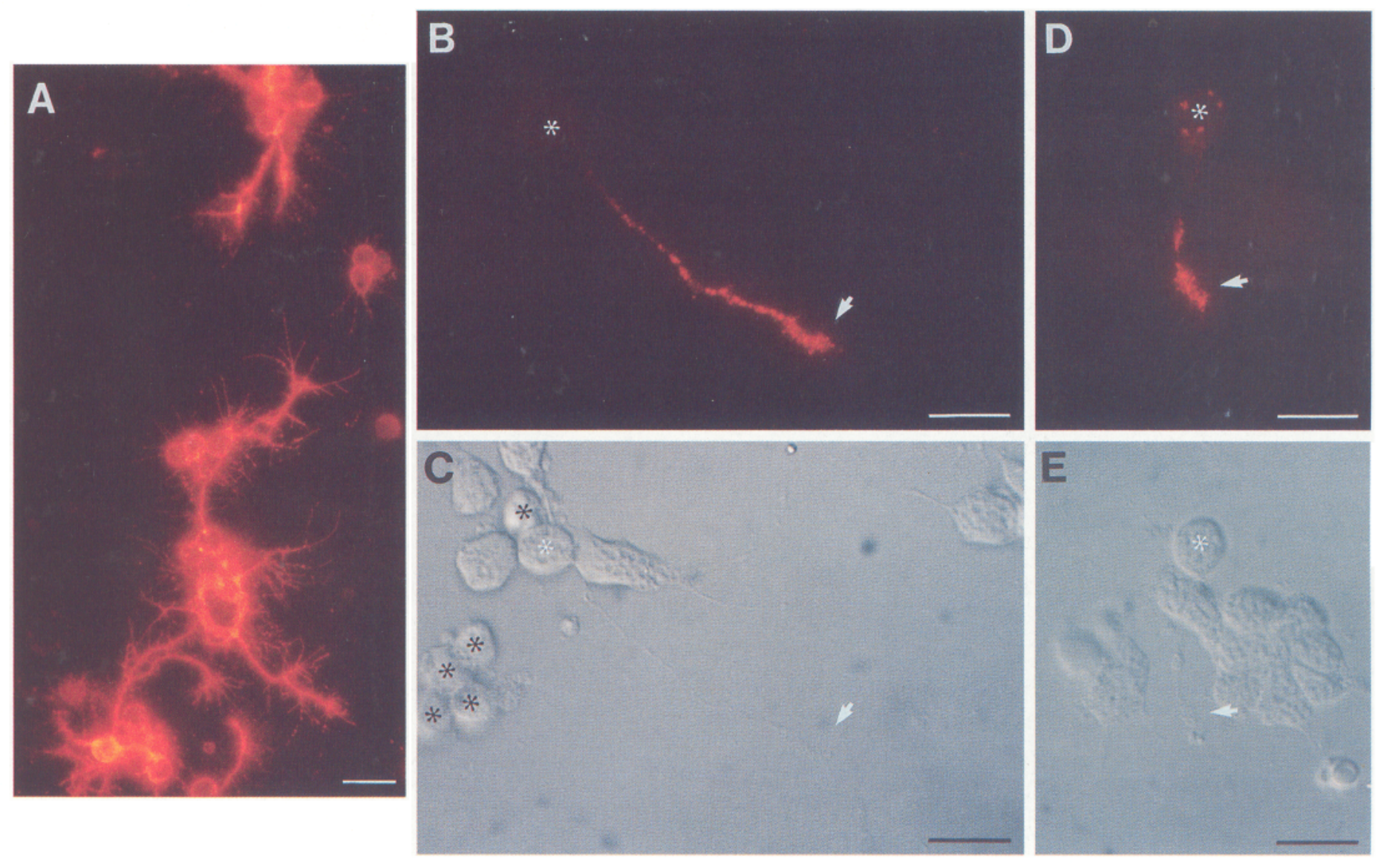

Figure 4. Restricted localization of Conulin to growth cones of cultured embryonic neurons. $A$, General view of a culture labeled with the neuronal marker anti-HRP. Long neurites and profuse filopodial extensions are achieved in $48 \mathrm{hr}$ of culture. $B, C$, mAb 7D2 labeling performed after fixation in the absence of detergents $(B)$ and DIC optics view of the same field $(C)$ show the restriction of Conulin to the distal portion of the neurite. The cell body of a neuron expressing Conulin is indicated with a white asterisk, and black asterisks identify non-neuronal cells as detected by anti-HRP labeling. White arrows indicate the nerve growth cone. $D, E$, Labeling of fixed and permeabilized cultures shows the intracellular vesicular labeling in the soma in addition to the growth cone restriction of Conulin. The cell body of the labeled neuron is indicated with a white asterisk. White arrows point to the nerve growth cone. Scale bars: $A, 30 \mu \mathrm{m} ; B-E, 20 \mu \mathrm{m}$.

reducing or nonreducing conditions. No change in mobility was observed (Fig. $7 B$ ), suggesting an absence of internal disulfide bonds and that Conulin is not part of a covalently linked multimolecular complex. In the same experiment, the grasshopper glycoprotein Lazarillo was efficiently deglycosylated and its electrophoretic mobility changed under nonreducing conditions (see Fig. 4 of Ganfornina et al., 1995).

\section{Conulin is secreted from nerve growth cones}

Although biochemical experiments and some expression features suggest at least a partial secretion of Conulin from growth cones, a direct demonstration of that secretion remains difficult in the embryo. However, in cultured neurons, labeling with mAb 7D2 clearly indicates such a release in the form of a cloud of spotty appearance surrounding outgrowing neurites. Figure $8 \mathrm{~A}$ shows an example of a neuron with two neurites labeled with anti-HRP (green). One of the growth cones (arrow) shows Conulin (red) as a suspension of particles that could have been released by this growth cone. Likewise, a cloudlet of 7D2-positive particles is surrounding the second neurite, for which its more complex growth cone is indicated by a triangle. We interpret this observation as a transient release of Conulin that has been left behind the extending growth cone, which agrees with our observations on whole-mount embryos described above (see Fig. 3I).

The question remains whether Conulin is truly secreted or whether the disperse labeling reflects a punctate and irregular pattern on the surface of filopodia. In some cases, 7D2-positive neurons are seen displaying Conulin strictly on the surface of filopodia (data not shown). This labeling, which clearly contrasts

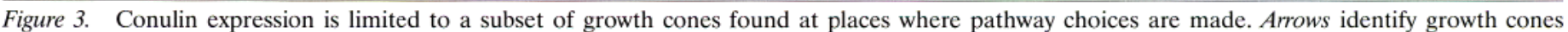

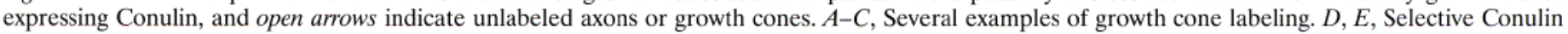

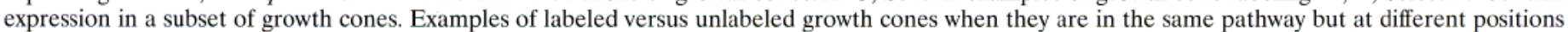

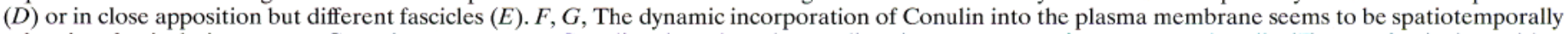

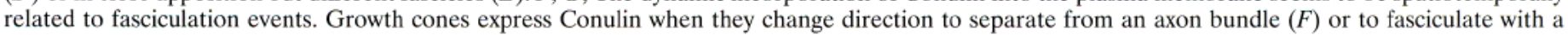

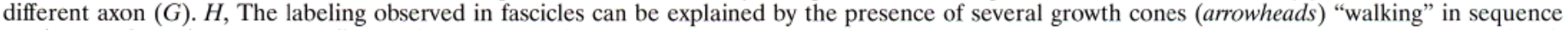

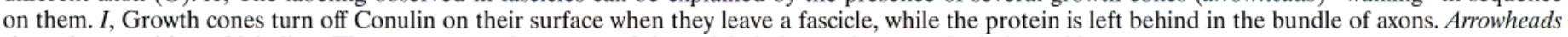
show the transition of labeling. The open arrow shows one of the unlabeled growth cones. Scale bars, $20 \mu \mathrm{m}$. 


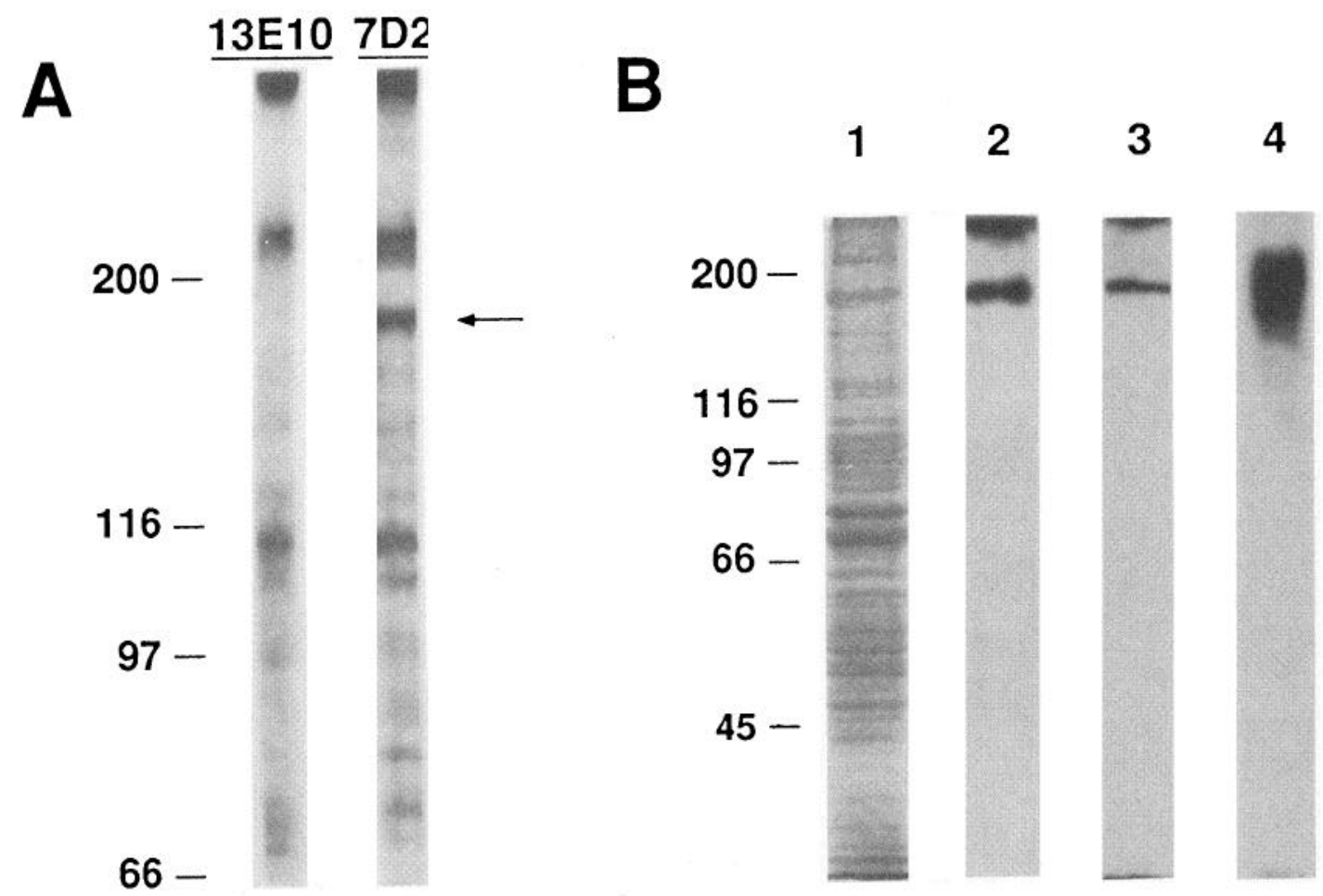

Figure 5. mAb 7D2 identifies a protein of $M_{\mathrm{r}} 190 \times 10^{3}$ in embryonic detergent-soluble fractions. $A$, Immunoprecipitation with mAb 7D2 from iodinated, detergent-soluble proteins of embryos at $45 \%$ of development. $13 \mathrm{E} 10$ is another mAb used to show nonspecific trapping of proteins. Arrow points to a specific protein of $M_{\mathrm{r}} 190 \times 10^{3}$ recognized by mAb 7D2. B, Immunoblot analysis in $45 \%$ (2) and $70 \%$ development (3) detergent-soluble proteins. Lane 1 is a Coomassie-stained gel of the same protein preparation. Lane 4 shows an immunoblot of the purification of Conulin by affinity chromatography from the detergent-soluble fraction of embryonic lysates. Spread appearance of the band probably is caused by protein overloading and/or partial degradation. $M_{\mathrm{r}}$ markers $\left(\times 10^{-3}\right)$ are shown on the left.

with the labeling observed in Figure $8 A$, is similar to the pattern obtained with other antibodies recognizing proteins that are present on the surface of filopodia (mAb 10E6 anti-Lazarillo; anti-HRP, see Fig. $4 A$ ) and indicates that it is actually the release of Conulin that produces the dispersed labeling. The cellular distribution of the labeling observed in dissociated cells is in fact heterogeneous. Cells with somatic surface labeling, cells labeled at the filopodial surface, others with the labeled particles emanating from the neurite, as well as cells with Conulin restricted to the growth cone can be seen in a single culture. These labeling patterns, except for the growth cone-specific one, were never observed in whole-mount embryos.

As stated earlier, mAb 7D2 labels embryos in vivo, suggesting a membrane surface location of the antigen. However, the labeling pattern under these conditions (Fig. $8 C$ ) differs from the pattern observed in fixed embryos (Fig. $8 B$ ). A diffuse labeling spreading outside the ganglia and accumulating in the appendage cavities (Fig. $8 C$, curved arrows) is accompanied by a weaker CNS fascicle labeling (Fig. 8C, arrow), suggesting that Conulin is being detached from its confinement in the CNS. Nevertheless, when embryos are incubated in the absence of the $\mathrm{mAb}$ in vivo for the same amount of time before fixation and then are labeled with mAb 7D2 without permeabilization, the standard CNS labeling appears as in Figure $8 B$. Similarly, immunocytochemistry with $\mathrm{mAb} 7 \mathrm{D} 2$ on live dissociated neurons consistently gives no labeling (Fig. $8 D, E$ ). This indicates that the difference in fixed versus in vivo labeling observed in both embryos and cultured neurons is attributable to a removal of Conulin from the growth cone surface that is triggered by mAb 7D2. These results support the hypoth- esis that Conulin is a protein secreted from a subset of growth cones at specific times and places in the developing grasshopper embryo.

\section{DISCUSSION}

The biochemical properties identify Conulin as a low-abundance protein of $M_{\mathrm{r}} 190 \times 10^{3}$ present in both the soluble and detergentsoluble fractions of grasshopper embryo homogenates. This protein does not appear to be glycosylated heavily with either $\mathrm{N}$ - or $\mathrm{O}$-linked oligosaccharides or with sialic acid. Conulin behaves as a peripheral membrane protein associated with the extracellular side of the plasma membrane by noncovalent and nonhydrophobic forces. However, this association seems to be weak, and Conulin is released easily to the extracellular environment.

The developmental expression pattern of Conulin reflects three important features. (1) It is restricted to the ganglionic neuropil of the CNS and is absent in longitudinal connectives and peripheral nerves. The expression is limited to a particular period of embryonic development, when most axonal pathways are being established. (2) Conulin can be found on the plasma membrane of neurons but also is secreted to the extracellular surroundings. (3) The surface expression of Conulin is restricted to the leading edge of growing neurites, the nerve growth cones.

\section{Presence of Conulin in growth cones}

The current catalog of growth cone-specific molecules is small. Some cytoskeletal proteins related to the motor activity of the growth cone such as $\alpha$-tubulin (Ahmad et al., 1993) and some actin-binding proteins (Lin et al., 1994) are located mainly at the 
A

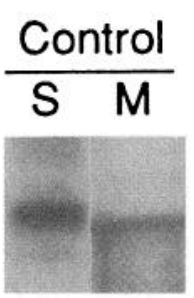

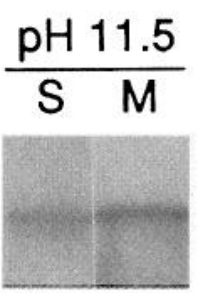

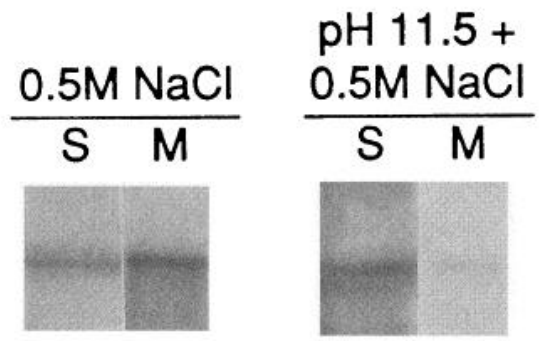

$\mathrm{B}$

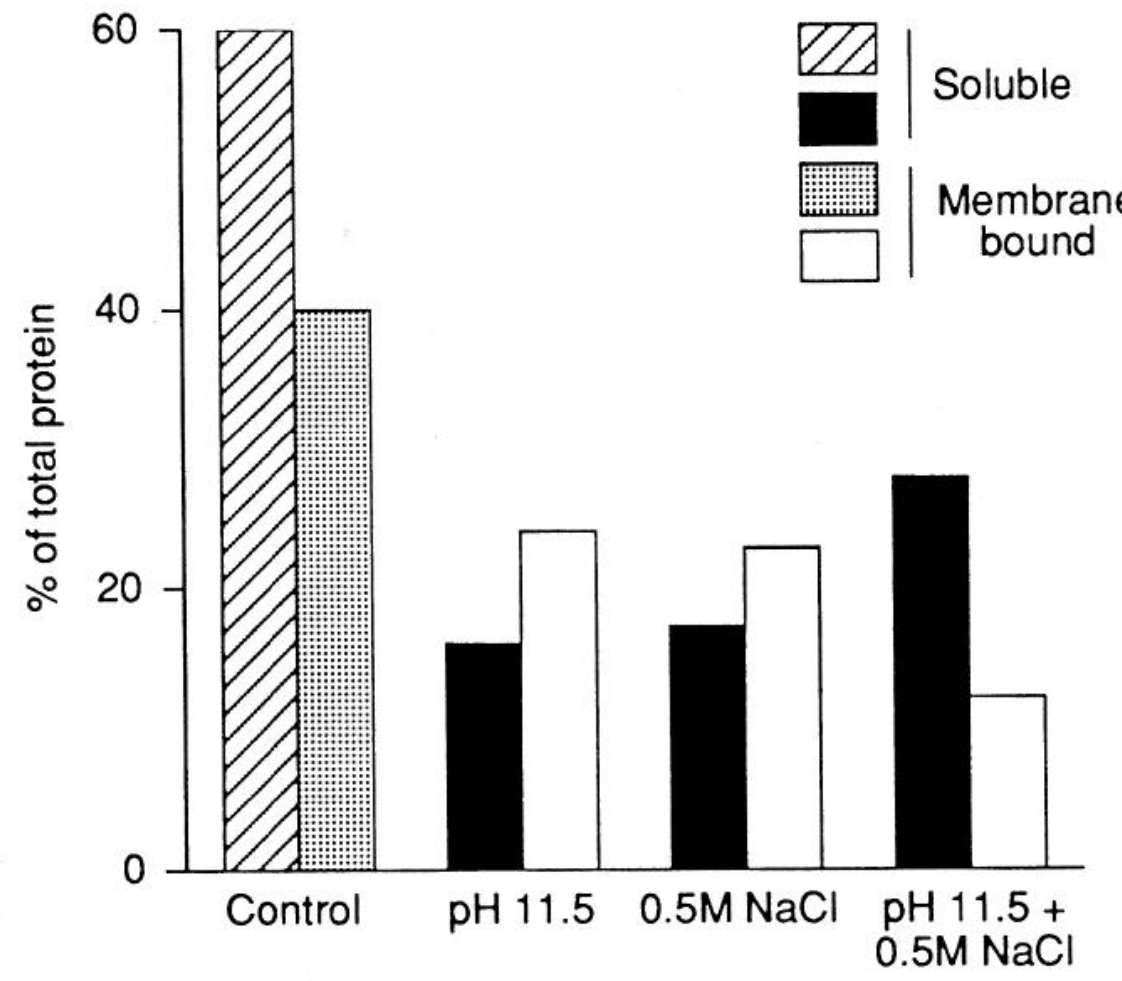

Figure 6. Conulin is also present in the soluble fraction of lysates and can be released easily from membranes. $A$, Immunoblot analysis of Conulin present in the membrane-bound $(M)$ and soluble $(S)$ fractions in control conditions and after different extraction experiments from membranes. The control conditions refer to the standard membrane preparation procedure (see Materials and Methods), which results in a soluble fraction $(S)$ and a membrane fraction $(M)$ that is subjected to detergent solubilization. Subsequent extraction procedures are carried out on the control membrane-associated proteins, and each one renders a soluble and a membrane fraction. $B$, Quantitative analysis of the results displayed in $A$. Band intensity was measured by densitometry, each measurement subtracted from the background and represented as a percentage of the total protein (i.e., soluble + membrane bound + extracted from membranes).

growth cone region but in a ubiquitous way in every neuron. The intermediate filament protein Tanabin is restricted to the axons and growth cones of a subset of neurons in early Xenopus embryos (Hemmati-Brivanlou et al., 1992) and is postulated to function in axon guidance by interacting with the navigational apparatus of the growth cone or with other cytoskeletal proteins. Likewise, microtubule-associated protein MAP1b, a protein essential for axonal elongation, appears to be concentrated at the growth cone of sympathetic neurons, where it might regulate microtubule dynamics (Black et al., 1994).

A few proteins involved in signal transduction are reported to be more concentrated at the growth cone. The growth-associated phosphoprotein GAP-43 is expressed during development in both vertebrates and invertebrates (Fitzgerald et al., 1991; Neel and Young, 1994). It is associated with outgrowth by activating G-proteins (Strittmatter et al., 1994). Similarly, the nonreceptor tyrosine kinase pp $60^{c-s r c}$ is concentrated in a subcellular fraction enriched in nerve growth cones, and $\mathrm{pp} 60^{c-s r c}$ antibodies preferentially bind to growth cones in primary cultures of chick retinal neurons (Maness et al., 1988). Its activated form is associated with other phosphoproteins and several growth cone membrane glyco- proteins (Hanissian et al., 1992). Moreover, other kinases of the src family also appear concentrated in growth cones (Bixby and Jhabvala, 1993).

The analysis of growth cone membrane proteins isolated by subcellular fractionation reveals a specific pattern of glycoproteins unique to the growth cone fraction (Greenberger and Pfenninger, 1986). By generating mAbs to growth cone membranes of fetal rat brain, a developmentally regulated membrane glycoprotein called 5B4 was identified (Ellis et al., 1985). This glycoprotein belongs to the N-CAM family (Ramos et al., 1989) and is specifically associated with regions of neuronal sprouting (Wallis et al., 1985). Interestingly, some of the proteins identified in the screening are present in growth cones from selected brain regions ( $\mathrm{Li}$ et al., 1992). Among them, the glycoprotein gp93 is specific to the brain, where it appears to be glycosylated differentially in particular neuronal populations. Gp93 is developmentally regulated in the molecular layer of the cerebellum and is prominently distributed on growing neurites and growth cones of cerebral cortical neurons (Quiroga and Pfenninger, 1994). M6, another cell-surface glycoprotein found by making mAbs against mouse cortex, is concentrated at nerve growth cones (Lagenaur et al., 1992), although it 

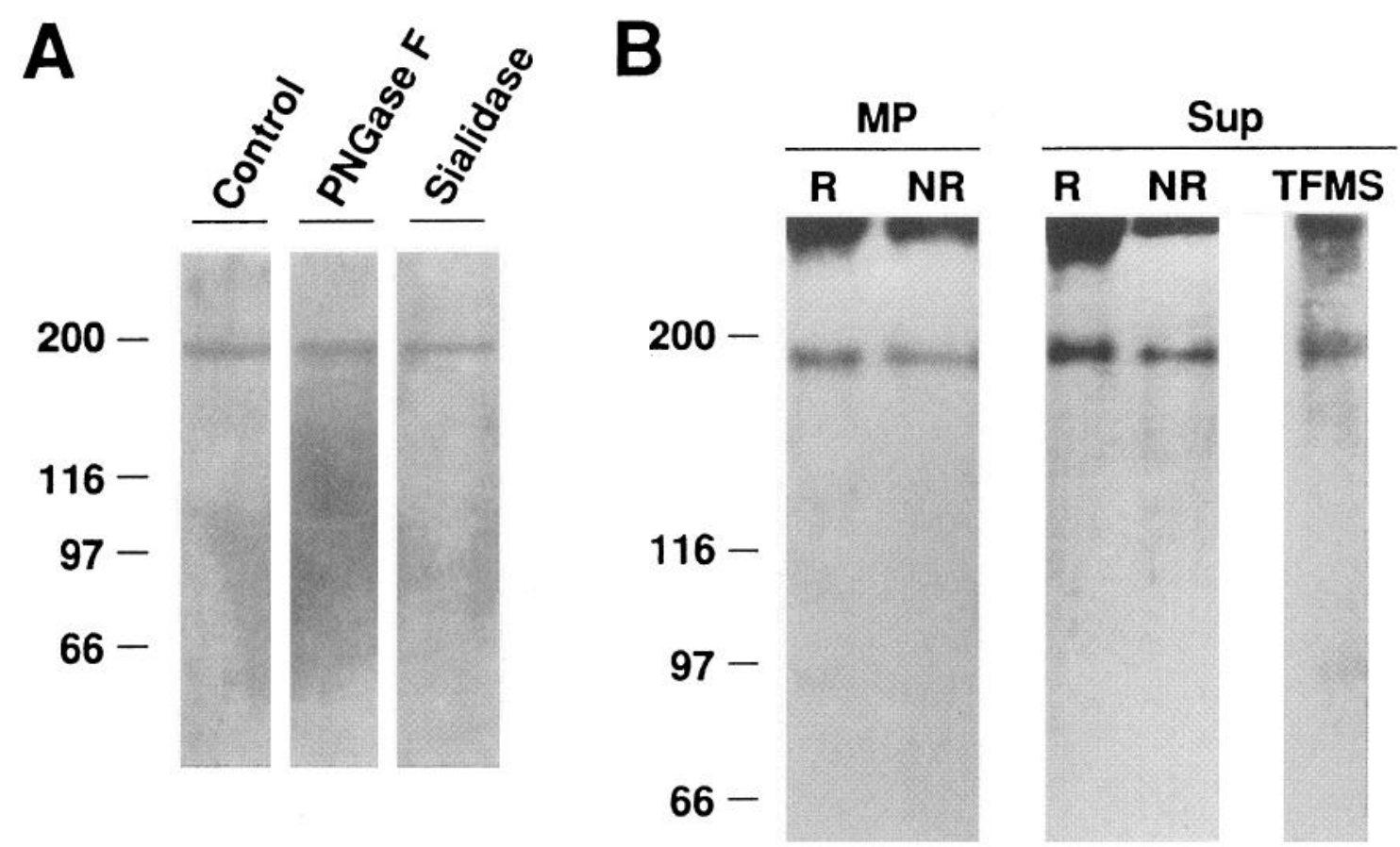

Figure 7. Conulin is not glycosylated significantly and is not modified by treatment with reducing agents. $A$, Enzymatic deglycosylation experiments analyzed by immunoblot. Neither PNGase $\mathrm{F}$ nor sialidase modifies the $M_{\mathrm{r}}$ of Conulin. $B$, Reducing $(R)$ versus nonreducing $(N R)$ electrophoretic separation of the 7D2 protein in both detergent-soluble $(M P)$ and soluble fractions (Sup). Chemical deglycosylation by TFMS of the soluble form of the protein does not change its electrophoretic mobility. $M_{\mathrm{r}}$ markers $\left(\times 10^{-3}\right)$ are shown on the left.

is also present throughout the CNS and other non-neuronal tissues.

The data presented so far highlight the existence of proteins concentrated in vertebrate growth cones and some evidence for their selective presence in definite neuronal populations. Nevertheless, the lack of molecules reported to be restricted to growth cones in invertebrate nervous systems is striking, considering that their simplicity has favored the study of developmental mechanisms at the level of single identified cells. Conulin is a membrane protein expressed by a subset of growth cones and developmentally regulated with a temporal window that reflects a possible role in axon pathfinding. However, Conulin is not targeted to the surface of pioneer neurons during the establishment of the axonal scaffold, but it is present on the growth cones of follower neurons. From this property, we hypothesize a role for Conulin in fasciculative guidance. Another important expression feature is the exclusive surface localization in the CNS, although we can detect vesicles containing Conulin in neuronal clusters of the peripheral nervous system (PNS) in the body wall. Moreover, identified motoneurons exiting through the $\mathrm{SN}$ express Conulin on their surface only during the intraganglionic trajectory, but never after they join to form the peripheral nerve. These results suggest that Conulin is needed by outgrowing neurites only when they are traveling through the ganglia. The ganglion is indeed a highly complex territory, where an incoming growth cone is confronted with a large number of axon fascicles from which to select an appropriate pathway to follow. This idea is further supported both by the absence of Conulin expression on growth cones along the longitudinal connectives, another fascicular highway without branches, and by the striking localization of a large fraction of 7D2-positive growth cones at the corners and lateral boundaries of the orthogonal scaffold, places of pathway decisions.

\section{Secretion of Conulin from nerve growth cones}

The biochemical and immunocytochemical results suggest that Conulin is secreted. A set of large vesicles is often observed in the soma and along neurites. These vesicles are quite unique to the 7D2-labeling pattern, and none of a total of $10 \mathrm{mAbs}$ against surface proteins we have tested exhibits a similar pattern under the permeabilization conditions used for mAb 7D2. We consider them to be secretory vesicles transporting Conulin from the cell body to the growth cone. Craig et al. (1995) have described a similar punctate labeling of a protein targeted to the growth cone in transfected hippocampal neurons. Labeling becomes restricted to the cell body after blocking the transit of membrane proteins through the Golgi apparatus, suggesting that they are vesicles transporting proteins from their site of synthesis to the plasma membrane at the growth cone. The secretion of Conulin, demonstrated in dissociated neurons as a cloud around the growth cone, contrasts with the diffuse but circumscribed labeling around growth cones obtained with mAb 7D2 in whole-mount embryos. Because that labeling is observed under conditions that preclude the access of the antibody to the cytoplasm, it suggests that in the embryo Conulin is trapped somehow in the extracellular matrix adjacent to the growth cone membrane. The failure to detect Conulin in the medium of cultured grasshopper embryos by immunoblot analysis (data not shown) also supports this view. Likewise, Conulin appears not to float freely in the supernatant of cultured neurons; rather, it tends to adhere to the culture substrate around the growth cones. Preliminary experiments analyzing this property indicate that Conulin seems to bind to laminin and fibronectin but that it also can attach to glass (data not shown).

Secreted molecules have been described which help developing axons to grow and organize a precise connectivity. Although the 

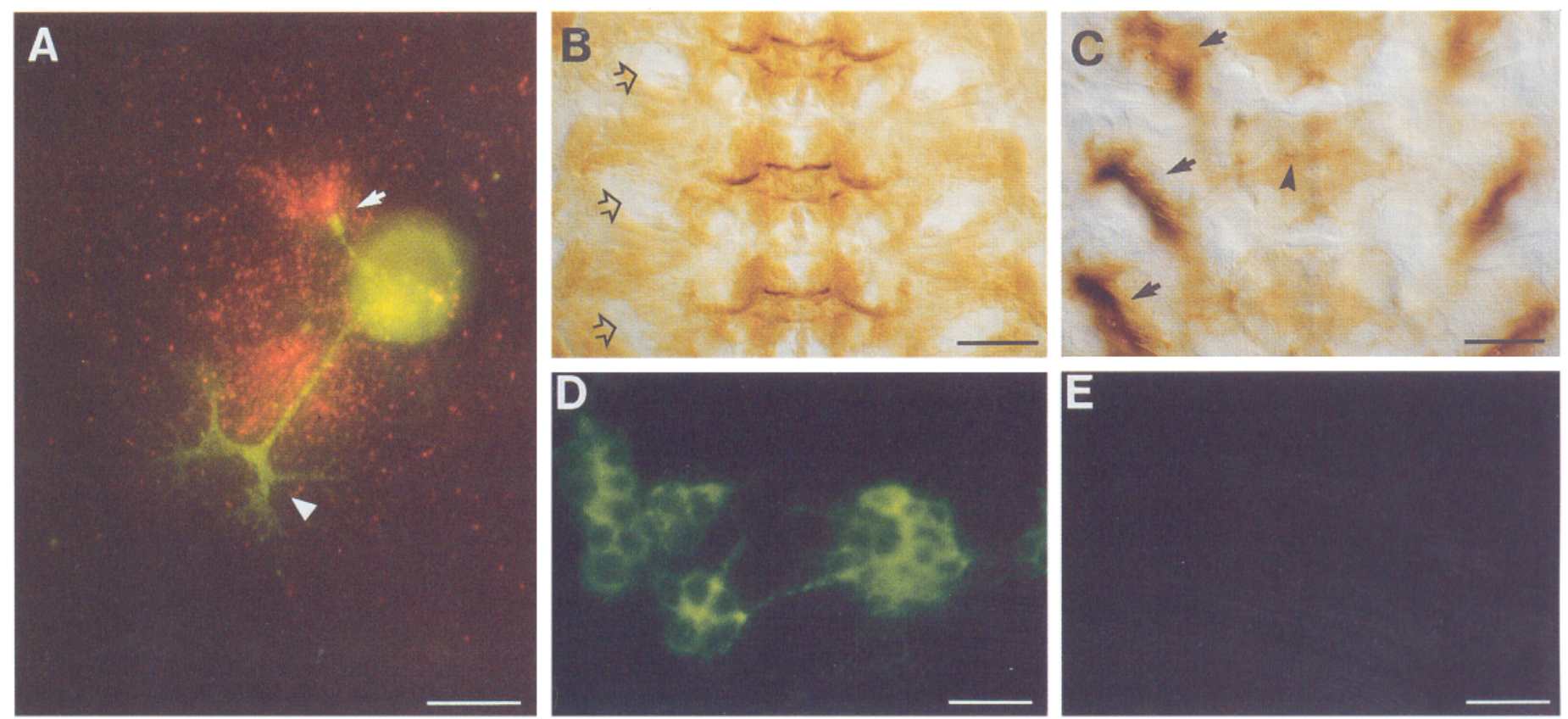

Figure 8. Conulin is released from nerve growth cones, and this process is facilitated by mAb 7D2. A, Double-labeling in the absence of detergents of a neuron releasing Conulin to the extracellular environment. Anti-HRP labeling (green) highlights the entire neuronal surface including filopodia. Conulin is observed (red) as a cloud of spots spreading from one of the growth cones (arrow) or left behind the growth cone of the second neurite (triangle). B, Thoracic segments of an embryo at $45 \%$ development fixed and labeled with mAb 7D2. Open arrows identify the celomic cavities of the legs. $C$, When embryos from the same clutch are exposed in vivo to mAb 7D2, CNS labeling almost disappears. Arrowhead denotes one of the few fascicles that remains labeled. Instead, labeling has accumulated in the celomic cavities of the legs (arrows). $D, E$, In vivo double-labeling of neurons in culture with fluorescein isothiocyanate-conjugated anti-HRP $(D)$ and $\mathrm{mAb} 7 \mathrm{D} 2$ revealed with Cy3-conjugated secondary antibody $(E)$. No labeling is observed with mAb 7D2. Scale Bars: $A, 15 \mu \mathrm{m} ; B, C, 150 \mu \mathrm{m} ; D, E, 30 \mu \mathrm{m}$.

source of these molecules is mainly non-neuronal cells, substances have been found that are released from developing growth cones and are involved in neurite outgrowth. Neurotransmitters, the archetypal molecules liberated by mature axon terminals, are also released by growth cones during development and have been involved in target recognition by embryonic Xenopus motoneurons via an activity-dependent mechanism (Sun and Poo, 1987). Cell-derived proteases are currently known to be secreted by developing growth cones and involved in neurite outgrowth and guidance (Seeds et al., 1992). The molecular nature of Conulin is not known currently. However, its biochemical properties and developmental expression pattern rule out the possibility of Conulin being a neurotransmitter. Similarly, we have no current data supporting the function of Conulin as a protease.

The labeling pattern, although based on static observations, suggests a transitory expression of Conulin. An estimation based on the average developmental lag between consecutive thoracic ganglia is that Conulin is present on the surface of a given growth cone for a maximum of $\sim 5 \mathrm{hr}$, which represents $\sim 20 \mu \mathrm{m}$ according to the average rate of growth cone extension in the grasshopper CNS (Myers and Bastiani, 1993). This agrees with the observations of growth cones, in both whole-mount embryos and dissociated neurons, that appear unlabeled ahead of a diffuse Conulin labeling left behind the extending growth cone.

Our observations suggest the existence of a dynamic cycle of Conulin expression, the details and implications of which we are continuing to study. A subset of neurons synthesize Conulin and initially store it in vesicles. Once the pioneer neurons have established the axonal scaffold, and possibly upon reception of signals from other axons, Conulin-loaded vesicles are targeted to specific growth cones. The protein is secreted but remains associated with the pericellular space. At that location, Conulin could be functionally involved in the recognition events preceding selective fasciculation. It could act as a receptor for environmental signals or, because of its secreted nature, equip growth cones with a way of modifying their surroundings. Once the growth cone has advanced beyond a particular region of a fascicle, Conulin targeting to the membrane is turned off rapidly. The fate of the protein then is left to processes that modify or degrade it at a seemingly high rate. This rapid turnover provides the highly dynamic growth cones with a fine spatiotemporal regulation of Conulin.

The view of the growth cone as a structure apart from the neurite in form and behavior predicts a unique biochemical composition and poses the question: Do growth cone-specific molecules exist? This question has been examined repeatedly (Bray and Hollenbeck, 1988) without a definitive answer. The search has recently revealed some candidate molecules that appear to be more concentrated at the leading edge of neurites. The discovery of Conulin confirms the existence of proteins specific for the nerve growth cone and reinforces the idea that this dynamic structure provides neurons with a higher order of specificity for sensing and processing positional information during axonal pathfinding.

\section{REFERENCES}

Ahmad FJ, Pienkowski TP, Baas PW (1993) Regional differences in microtubule dynamics in the axon. J Neurosci 13:856-866.

Bastiani MJ, Harrelson AL, Snow PM, Goodman CS (1987) Expression of Fasciclin I and II glycoproteins on subsets of axon pathways during neuronal development in the grasshopper. Cell 48:745-755.

Bentley D, Keshishian H, Shankland M, Toroian-Raymond A (1979) Quantitative staging of embryonic development of the grasshopper, Schistocerca nitens. J Embryol Exp Morphol 54:47-74.

Bixby JL, Jhabvala P (1993) Tyrosine phosphorylation in early embryonic growth cones. J Neurosci 13:3421-3432. 
Black MM, Slaughter T, Fischer I (1994) Microtubulc-associated protein ib (MAP-1b) is concentrated in the distal region of growing axons. $J$ Neurosci 14:857-870.

Bray D (1970) Surface movements during the growth of single explanted neurons. Proc Natl Acad Sci USA 65:905-910.

Bray D (1973) Branching patterns of individual sympathetic neurons in culture. J Cell Biol 56:702-712.

Bray D. Hollenbeck PJ (1988) Growth cone motility and guidance. Annu Rev Cell Biol 4:43-61.

Carpenter EM, Bastiani MJ (1990) Expression and characterization of nervous system antigens in grasshopper cmbryos. Soc Ncurosci Abstr 16:303.

Craig AM, Wyborski RJ, Banker G (1995) Preferential addition of nowly synthesized membrane protein at axonal growth cones. Nature 375:592-594.

Davenport RW, Dou P, Rehder V, Kater SB (1993) A sensory role for ncuronal growth cone filopodia. Nature 361:721-724.

Davis L, Rchder V, Kater SB (1992) Autonomous activities of the neuronal growth concs. In: The nerve growth cone (Letourneau PC, Katcr SB, Macagno ER, eds), pp 133-149. New York: Raven.

Dodd J, Morton SB, Karagogeos D, Yamamoto M, Jessell TM (1988) Spatial regulation of axonal glycoprotein expression on subsets of $\mathrm{cm}$ bryonic spinal neurons. Neuron 1:105-116.

Ellis L, Wallis I, Abreu E, Pfenninger KH (1985) Nerve growth cones isolated from fetal rat brain. IV. Preparation of a membrane subfraction and identification of a membrane glycoprotein expressed on sprouting neurons. J Cell Biol 101:1977-1989.

Fitzgerald M, Reynolds ML, Benowitz LI (1991) GAP-43 expression in the developing rat lumbar spinal cord. Neuroscience 41:187-199.

Ganfornina MD, Sánchez D, Bastiani MJ (1995) Lazarillo, a GPI-linked surface glycoprotein restricted to a subset of neurons in the grasshopper embryo, is a new member of the lipocalin family. Development 121:123-134.

Goodman CS, Shatz CJ (1993) Developmental mechanisms that generate precise patterns of neuronal connectivity. Neuron [Suppl] 10:77-98

Greenberger LM, Pfenninger KH (1986) Membrane glycoproteins of the nerve growth cone: diversity and growth-associated oligosaccharides. J Cell Biol 103:1369-1382.

Hanissian SH, Chatila T, Sahyoun NE (1992) Association of neuronal pp $60^{\mathrm{c}-\mathrm{src}}$ with growth cone glycoproteins of rat brain. J Neurobiol $23: 803-813$.

Hemmati-Brivanlou A, Mann RW, Harland RM (1992) A protein expressed in the growth cones of embryonic vertebrate neurons defines a new class of intermediate filament protein. Ncuron 9:417-428.

Hortsch M, Goodman CS (1990) Drosophila Fasciclin I, a neural cell adhesion molecule, has a phosphatidylinositol lipid membrane anchor that is developmentally regulated. J Biol Chem 265:15104-15109.

Karlstrom RO, Wilder LP, Bastiani MJ (1993) Lachesin: an immunoglobulin superfamily protein whose expression correlates with neurogenesis in grasshopper embryos. Development 118:509-522.

Kolodkin AL, Matthes DJ, O'Connor TP, Patel NH, Admon A, Bentley D, Goodman CS (1992) Fasciclin. IV. Sequence, expression, and function during growth cone guidance in the grasshopper embryo. Neuron $9: 831-845$
Lagenaur C, Kunemund V, Fischer G, Fushiki S, Schachner M (1992) Monoclonal M6 antibody interferes with neurite extension of cultured neurons. J Neurobiol 23:71-88

Laurent G, Scymour-Laurent KJ, Johnson K (1993) Dendritic excitability and voltage-gated calcium current in locust nonspiking local interncurons. J Neurophysiol 69:1484-1498.

Li H, Quiroga S, Pfenninger KH (1992) Variable membrane glycoproteins in different growth cone populations. J Neurosci 12:2393-2402.

Lin C, Thompson CA, Forscher P (1991) Cytoskeletal reorganization underlying growth cone motility. Curr Opin Neurobiol 4:640-647.

Maness PF, Aubry M, Shores CG, Frame L, Pfenninger KH (1988) c-src gene product in developing rat brain is enriched in nerve growth cone membranes. Proc Natl Acad Sci USA 85:5001-5005.

Myers PZ, Bastiani MJ (1993) Growth cone dynamics during the migration of an identified commissural growth cone. J Neurosci $13: 127-143$

Neel VA, Young MW (1994) igloo, a GAP-43-related gene expressed in the developing nervous system of Drosophila. Development 120:2235-2243.

Patel NH, Snow PM, Goodman CS (1987) Characterization and cloning of Fasciclin. III. A glycoprotein expressed on a subset of neurons and axon pathways in Drosophila. Cell 48:975-988.

Poo M, Quillan M (1992) Growth orientation and transmitter secretion by nerve growth cones. In: The nerve growth cone (Letourneau PC, Kater SB, Macagno ER, eds), pp 231-236. New York: Raven.

Ouiroga S, Pfenninger KH (1994) Characterization of gp93, a novel highly heterogeneous glycoprotein present in growth cone membranes. J Neurochem 63:1150-1158.

Ramos P, Safaci R, Kayalar C, Ellis L (1989) Isolation and sequence of $\lambda \mathrm{gt} 11$ cDNA clones encoding the 5B4 antigen expressed on sprouting neurons. Mol Brain Res 5:297-303.

Sánchez D, Gantornina MD, Bastiani MJ (1995) Spatial restriction of the lipocalin Lazarillo and its role in axonal pathfinding in the grasshopper embryo. Development 121:135-147.

Seaver E, Karlstrom RO, Bastiani MJ (1991) The restricted spatial and temporal expression of a nervous system-specific antigen involved in axon outgrowth during development of the grasshopper. Development 111:881-893.

Seeds NW, Haffke SP, Hawkins RL, Krystosck A, McGuire PG, Verrall S (1992) Neuronal growth cones: battering rams or lasers? In: 'l'he nerve growth conc (Letourneau PC, Kater SB, Macagno ER, eds), pp $219_{-}$ 229. New York: Raven.

Strittmatter SM, Igarashi M, Fishman MC (1994) GAP-43 aminoterminal peptides modulate growth cone morphology and ncurite outgrowth. J Neurosci 14:5503-5513.

Sun Y, Poo M (1987) Evoked release of acetylcholine from the growing embryonic neuron. Proc Natl Acad Sci USA 84:2540-2544.

Tessier-Lavigne M (1994) Axon guidance by diffusible repellants and attractants. Curr Opin Genet Dev 4:596-601.

Wallis I, Ellis L, Suh K, Pfenninger KH (1985) Immunolocalization of a neuronal growth-dependent membrane glycoprotein. J Cell Biol 101 $1990-1998$. 